BMJ Open

Sport \&

Exercise

Medicine

\section{Effectiveness of return to activity and return to school protocols for children postconcussion: a systematic review}

\author{
Carol DeMatteo (D) , ${ }^{1,2}$ E Dimitra Bednar (D) , ${ }^{2,3}$ Sarah Randall, ${ }^{2}$ Katie Falla ${ }^{2}$
}

To cite: DeMatteo C, Bednar ED, Randall S, et al. Effectiveness of return to activity and return to school protocols for children postconcussion: a systematic review. BMJ Open Sport \& Exercise Medicine 2020;6:e000667. doi:10.1136/ bmjsem-2019-000667

- Additional material is published online only. To view please visit the journal online (http://dx.doi.org/10.1136/ bmjsem-2019-000667).

Accepted 6 February 2020

Check for updates

\section{(C) Author(s) (or their} employer(s)) 2020. Re-use permitted under CC BY-NC. No commercial re-use. See rights and permissions. Published by BMJ.

${ }^{1}$ School of Rehabilitation Science, McMaster University, Hamilton, Ontario, Canada ${ }^{2}$ CanChild Centre for Childhood Disability Research, McMaster University, Hamilton, Ontario, Canada

${ }^{3}$ Michael G DeGroote School of Medicine, McMaster University, Hamilton, Ontario, Canada

\section{Correspondence to} Dr Carol DeMatteo; dematteo@mcmaster.ca

\section{ABSTRACT}

Objective To determine the effects of following return to activity (RTA) and return to school (RTS) protocols on clinical outcomes for children with concussion. The 12 subquestions of this review focus on the effectiveness of protocols, guidelines and recommendations, and the evidence supporting content of the protocols including rest, exercise and school accommodations.

Design Systematic review.

Data sources PubMed, MEDLINE, EMBASE, CINAHL, ERIC and manual reference list check.

Eligibility criteria for selecting studies Studies were included if they evaluated RTA or RTS protocols in children aged 5-18 years with a concussion or if they reported a rigorous study design that provided evidence for the recommendations. Included studies were original research or systematic reviews. Articles were excluded if they did not report on their methodology or included participants with significant neurological comorbidities. Results The literature search retrieved 198 nonduplicate articles and a total of 13 articles were included in this review. Despite the adoption of several RTS and RTA protocols in clinical practice there is little evidence to determine their efficacy in the paediatric population.

Summary The current data support the recommendation that children in the acute stage postconcussion should undergo 1-2 days physical and cognitive rest as they initiate graduated RTA/RTS protocols. Prolonged rest may increase reported symptoms and time to recovery. Further interventional studies are needed to evaluate the effectiveness of RTA/RTS protocols in youth with concussion.

\section{INTRODUCTION}

Concussion or mild traumatic brain injury in children is a significant public health concern. ${ }^{1}$ The incidence of concussion within Ontario is greatest in children: approximately 72 out of 1000 children aged 5-12 years and 60 out of 1000 children aged 13-17 years will experience a concussion each year. $^{23}$ The International Concussion in Sport Group (CISG) defines concussion as a 'traumatic brain injury induced by biomechanical forces'. Concussion can be caused by a direct injury to the head, face, neck or elsewhere on the body with an impulsive force transmitted to the head. ${ }^{4}$ Research efforts

\section{Summary box}

What is already known?

- Paediatric return to activity (RTA) protocols should be more conservative than those of an adult athlete.

- A balance of cognitive and timely return to school (RTS) need to be considered in protocols returning children to school after concussion.

- RTA/RTS protocols remain the primary management strategy for children with postconcussion.

\section{What are the new findings?}

- Children with acute concussion should undertake relative rest for 24-48 hours followed by a progressive return to non-contact activity as long as symptoms do not worsen or increase.

- Prolonged, complete rest is not recommended and can worsen symptoms or increase recovery time for children within the acute phase of concussion recovery.

- It is clear that protocols for children are different than those for adults and should be used accordingly.

- More evidence surrounding RTA and RTS outcomes (eg, length of recovery, quality of life, symptomatology, number of school modifications and so on) between children/youth who follow guidelines and those who do not, is warranted.

are concentrated towards the appropriate management of youth with concussion to facilitate quick resumption of routine daily activities including school and sport, to avoid repeat injury and second impact syndrome and to prevent prolonged symptoms and permanent neurocognitive sequalae. ${ }^{15-7}$

The research data are currently insufficient to advocate for the ideal management of return to school (RTS) and return to activity (RTA) in the paediatric population. ${ }^{5}$ Due to the variable clinical presentations and recovery trajectories associated with concussion, individualised management approaches are recommended and are based off of graduated protocols for RTA and RTS. ${ }^{4}$ Following the establishment of these protocols by expert consensus, ${ }^{1489}$ which now guide clinical practice, it is necessary to assess their efficacy. Inquiries already addressed in the literature 
include the evaluation of rest and RTA after concussion in unspecified populations, ${ }^{10}{ }^{11}$ a review of the differences in concussion management between children and adults, ${ }^{12}$ and associations among RTA and persistent postconcussive symptoms in adolescents. ${ }^{13-15}$ Despite the growing literature on the clinical management of children with concussion, there remains a lack of evidence evaluating the effectiveness of RTA and RTS protocols. ${ }^{16}$

The purpose of this systematic review was to determine the effects of following RTA or RTS protocols on the clinical outcomes of children with concussion. Twelve questions were categorised in relation to the effects of following RTA and RTS guidelines:

\section{Effectiveness of guidelines}

1. What are the effects of following RTA protocols/ guidelines on youth postconcussion?

2. What are the effects of following RTS protocols/guidelines on youth postconcussion?

3. Do children who follow RTA/RTS protocols/guidelines have shortened symptom time compared with children who do not follow guidelines?

4. Do children who follow RTA/RTS protocols/guidelines RTS/RTA faster than children who do not follow protocols?

5. Do children who follow RTA/RTS protocols/guidelines have increased quality of life compared with children who do not follow protocols?

\section{Content of guidelines}

Physical rest

6. What is the effect of physical rest postconcussion on outcomes including symptoms, emotions, recovery time, academic success and participation?

7. How much physical rest is recommended/what is the recommended duration of physical rest and what is the supporting evidence behind these recommendations? Cognitive rest

8. What is the effect of cognitive rest postconcussion on outcomes including symptoms, emotions, recovery time, academic success and participation?

9. How much cognitive rest is recommended/what is the recommended duration of cognitive rest and what is the supporting evidence behind these recommendations? Time progression through guidelines

10. What is the recommended time to progress through the stages of RTA and RTS guidelines?

Exertion/exercise

11. Is graded exercise/exertion of benefit in achieving a faster RTA?

12. Are school accommodations of benefit in having children RTS faster and with fewer academic challenges?

\section{METHODS}

\section{Study selection}

This study used the methodologies and procedures of a systematic review. A rigorous search of the literature was conducted (see online supplementary appendix A for search strategies), where three reviewers independently engaged in the literature screening process. The reviewers screened the titles and abstracts of retrieved records before obtaining the full-text articles for an in-depth second screen. Only academic peer-reviewed sources were included, and each record was critically appraised by two reviewers using the Centre for Evidence-Based Medicine (CEBM) critical appraisal guidelines and worksheets. ${ }^{1718}$ A third reviewer was available for consultation if consensus regarding inclusion could not be attained during the title and abstract screen or during the fulltext screen. Data abstraction was completed using custom worksheets created by a reviewer.

\section{Eligibility criteria}

Studies were eligible for inclusion if original RTA and/ or RTS protocols were assessed in children aged 5-18 years with an acute concussion, or if original research was conducted to provide evidence regarding content for the protocols. Peer-reviewed articles that employed any study design were included if they addressed 1 of the 12 questions of this review. The mechanism of injury did not have to be sport-specific since children can acquire a concussion from multiple modalities including falls or motor-vehicle accidents. Studies had to be published in English.

Due to the paucity of research on this topic, exclusion criteria were small. Studies were excluded if children had severe traumatic brain injuries that required hospital admission, or if the participants had a previous significant history of brain injury or neurodevelopmental delay. Articles were excluded if they did not report any scientific methodologies for their creation or assessment of RTA/RTS protocols.

\section{Literature search and information sources}

A systematic search of the literature was conducted in March 2019 to identify relevant published work from January 2013 until March 2019. This search was limited to records published since 2013 due to the findings of a scoping review ${ }^{6}$ that examined the existing literature on return to play and RTS guidelines for children and youth up to 2013. The databases PubMed, MEDLINE, EMBASE, CINAHL and ERIC were searched. Comprehensive search strategies with Boolean operators were built for each database and were informed by an expert health science librarian. Online supplementary appendix A shows the complete search strategies. The reference lists of retrieved articles were also searched to identify potentially relevant articles for inclusion that the electronic database search may have missed. An expert in the field was consulted to capture all critical publications.

\section{Critical appraisal of included articles}

Quantitative studies were critically reviewed using a 'Critical Review Form-Quantitative Studies'. ${ }^{17}$ Systematic reviews were assessed using the CEBM Systematic Review 
Guidelines. ${ }^{18}$ All included studies were assigned a level of evidence using the Oxford CEBM Levels of Evidence. ${ }^{19}$

\section{Data synthesis}

Data were synthesised narratively because it was not possible to complete a meta-analysis as the measured outcomes and statistical results varied greatly between included articles. Table 1 provides a summary of the included articles and how they addressed the objectives of this systematic review.

\section{RESULTS}

\section{Study selection}

The literature search retrieved 198 records published between January 2013 and March 2019 to be considered for inclusion. Title and abstract screening yielded 82 records. After full-text screening of the retrieved records, a total of 11 articles were fit for inclusion (figure 1). Four additional articles found based on expert knowledge of the field were included. Due to the current limitations of the literature, some questions were unable to be addressed.

\section{Effectiveness of guidelines}

What are the effects of following RTA protocols/guidelines?

One article evaluated the effects of following the Zurich Consensus Conference Concussion Guidelines for RTA after completing a standardised exercise test. ${ }^{20}$ The objective of this retrospective chart review and follow-up of 117 adolescent participants with concussion was to evaluate the Guidelines' efficacy for successful return to sport and school without the return of symptoms. ${ }^{20}$

The results of this retrospective case review found that following RTA guidelines predicted a successful return to sport without symptom exacerbation. On successful completion of the Buffalo Concussion Treadmill Test (BCTT) and then the Zurich Guidelines' Stages for RTA, no participants experienced symptom recurrence while progressing through the protocol or 2 months afterwards. ${ }^{20}$ All participants returned to sport successfully. A proportion of the participants $(42.9 \%)$ reported 'difficulty concentrating' on returning to the classroom following concussion. ${ }^{20}$

Given the methodological limitations of this study design and the high risk of recall and selection bias, this study was assigned as a low quality of evidence (Level 4; found in table 1). Further studies should be done to assess the effects of following RTA protocols.

What are the effects of following RTS protocols/guidelines?

No retrieved articles answered this question.

Do children who follow RTA/RTS protocols/guidelines have shortened symptom time compared with children who do not follow guidelines?

One article assessed if children who followed guidelines had shortened symptom time compared with children who did not follow guidelines. ${ }^{21}$ Increased adherence to RTA guidelines was associated with prolonged symptomatology or slower time to recovery compared with lower adherence to guidelines. ${ }^{21}$

This descriptive case series assessed treatment adherence and recovery time in 56 adolescent athletes after sport-related concussion (SRC) and used regression analysis to describe the relationship between adherence and time to recovery. ${ }^{21}$ Adherence to treatment recommendations was measured using patient self-reports of receptivity to the recommendations and frequency with which the recommendations were followed ${ }^{21}$ Recovery occurred faster in children who were less adherent to the recommendations for physical and cognitive rest from school and electronics. ${ }^{21}$

This evidence was rated as a low quality (Level 4; table 1) due to several shortcomings: it studied a convenience sample from a single hospital setting with almost $50 \%$ lost to follow-up, there was reliance on self-report from participants for outcome measures and there was a high risk of selection bias. ${ }^{21}$ The limitations of this single descriptive case series demonstrate the need for better quality research to determine if following RTA/RTS protocols confers shortened symptom time for children with concussion.

Do children who follow RTA/RTS protocols/guidelines RTS faster than children who do not follow protocols/guidelines?

No retrieved articles answered this question.

Do children who follow RTA/RTS protocols/guidelines have increased quality of life compared with children who do not follow protocols/guidelines?

No retrieved articles answered this question.

\section{Physical rest}

What is the effect of physical rest postconcussion on outcomes including symptoms, emotions, recovery time, academic success and participation?

Three studies assessed the effects of physical rest postconcussion on symptoms, recovery time and participation: one randomised controlled trial (RCT $)^{22}$ and two prospective cohort study. ${ }^{23}$ An immediate period of physical rest for 1-2 days postconcussion has been found to decrease reported symptoms, shorten recovery time and increase children's participation in school and activity.

One RCT evaluated the effects of different periods of rest in youth with concussion by comparing prolonged rest for 5 days to the usual standard of care (1-2 days rest) on outcomes including mean postconcussion symptom scores, the time to symptom resolution (time when Postconcussion Symptom Scale (PCSS) score $<7$ ) and physical activity. ${ }^{22}$ Prolonged physical rest increased recovery time and symptom scores, and decreased participation. ${ }^{22}$ The prolonged rest group took 6 days until symptom resolution while the usual care group took 4.75 days. ${ }^{22}$ The prolonged rest group also reported a greater mean PCSS score (13 PCSS units) compared with the usual care group (8 PCSS units) on the 10th day postinjury. ${ }^{22}$ Participants who rested for 1-2 days reported 
Table 1 Included articles that addressed questions of this systematic review

\begin{tabular}{lll}
\hline Question & Included articles & Objective \\
\hline $\begin{array}{l}\text { What are the effects of } \\
\text { following RTA guidelines/ } \\
\text { protocols? }\end{array}$ & Darling et al $^{20}$ & $\begin{array}{l}\text { Evaluated the Zurich } \\
\text { Consensus Guidelines for } \\
\text { RTA in adolescents with } \\
\text { concussion after they } \\
\text { successfully completed the } \\
\text { BCTT. }\end{array}$ \\
$\begin{array}{ll}\text { Do children who follow RTA } \\
\begin{array}{l}\text { RTS protocols have decreased } \\
\text { symptom time compared with } \\
\text { children who do not follow } \\
\text { guidelines? }\end{array}\end{array} \quad$ Moor et al ${ }^{21}$ & $\begin{array}{l}\text { Determined adherence } \\
\text { tendencies of adolescents }\end{array}$ \\
& & $\begin{array}{l}\text { to concussion management } \\
\text { strategies and if adherence } \\
\text { influenced recovery time. }\end{array}$
\end{tabular}

\begin{tabular}{|c|c|c|c|c|c|}
\hline \multirow[t]{3}{*}{$\begin{array}{l}\text { What is the effect of physical } \\
\text { rest postconcussion on } \\
\text { outcomes including symptom, } \\
\text { emotions, recovery time, } \\
\text { academic success and } \\
\text { participation? }\end{array}$} & Thomas et $a l^{22}$ & $\begin{array}{l}\text { Determined if prolonged } \\
\text { physical rest for } 5 \text { days } \\
\text { compared with usual care } \\
\text { (1-2 days physical rest) } \\
\text { improved concussion } \\
\text { recovery time and symptoms. }\end{array}$ & RCT & $\begin{array}{l}\text { Prolonged rest group reported a } \\
\text { greater mean PCSS score and } \\
\text { had a longer time to symptom } \\
\text { resolution than the usual care } \\
\text { group. Both groups reported } \\
\text { a similar decrease in physical } \\
\text { activity. }\end{array}$ & Level 1 \\
\hline & Taubman et a $\left.\right|^{23}$ & $\begin{array}{l}\text { Determined the effect of } \\
\text { delayed physical rest on } \\
\text { recovery time in children with } \\
\text { concussion. }\end{array}$ & Prospective cohort & $\begin{array}{l}\text { Immediate rest group had a } \\
\text { shorter time to clinical recovery } \\
\text { compared with the delayed rest } \\
\text { group. }\end{array}$ & Level 4 \\
\hline & Moser et $a l^{24}$ & $\begin{array}{l}\text { Examined the effects of } \\
\text { prescribed rest in adolescent } \\
\text { athletes with persistent } \\
\text { concussive symptoms. }\end{array}$ & Prospective cohort & $\begin{array}{l}\text { Symptoms improved } \\
\text { following rest for a majority } \\
\text { of participants. A significant } \\
\text { effect of rest on neurocognitive } \\
\text { and total symptom scores was } \\
\text { found. }\end{array}$ & Level 4 \\
\hline \multirow{4}{*}{$\begin{array}{l}\text { How much physical rest is } \\
\text { recommended/what is the } \\
\text { recommended duration of } \\
\text { physical rest and what is the } \\
\text { supporting evidence behind } \\
\text { these recommendations? } \\
\text { How much physical rest is } \\
\text { recommended/what is the } \\
\text { recommended duration of } \\
\text { physical rest and what is the } \\
\text { supporting evidence behind } \\
\text { these recommendations? }\end{array}$} & DeMatteo et al $(2015)^{8}$ & $\begin{array}{l}\text { Developed a protocol for } \\
\text { paediatric population's RTA. }\end{array}$ & $\begin{array}{l}\text { Protocol } \\
\text { developed and } \\
\text { modified from the } \\
\text { Zurich guidelines }\end{array}$ & $\begin{array}{l}\text { Conservative protocol } \\
\text { included a series of six steps } \\
\text { with the goal of resuming all } \\
\text { activity. Physical rest was } \\
\text { recommended for } 1 \text { week after } \\
\text { being symptom free. }\end{array}$ & Level 2 \\
\hline & Lumba-Brown et al ${ }^{1}$ & $\begin{array}{l}\text { Developed recommendations } \\
\text { for the management of } \\
\text { children with concussion. }\end{array}$ & $\begin{array}{l}\text { Guidelines } \\
\text { created based on } \\
\text { systematic review }\end{array}$ & $\begin{array}{l}\text { Recommended patients rest } \\
1-2 \text { days postconcussion } \\
\text { before beginning a gradual } \\
\text { schedule of subthreshold } \\
\text { activity. Graduated introduction } \\
\text { to non-contact and contact } \\
\text { activity is permitted so long as } \\
\text { they remain symptom-free. }\end{array}$ & Level 1 \\
\hline & Halstead et al ${ }^{25}$ & $\begin{array}{l}\text { Provided education on } \\
\text { current management of } \\
\text { children and adolescents with } \\
\text { concussion. }\end{array}$ & $\begin{array}{l}\text { Clinical report } \\
\text { created by expert } \\
\text { consensus }\end{array}$ & $\begin{array}{l}\text { Athletes with concussion } \\
\text { should be removed from play } \\
\text { immediately and undergo } \\
1-2 \text { days physical rest before } \\
\text { completing a stepwise return-to } \\
\text { sport programme. }\end{array}$ & Level 4 \\
\hline & McCrory et al ${ }^{4}$ & $\begin{array}{l}\text { Provided evidence-based } \\
\text { recommendations to } \\
\text { guide clinical practice of } \\
\text { sport-related concussion } \\
\text { management. }\end{array}$ & $\begin{array}{l}\text { Consensus } \\
\text { statement based } \\
\text { on systematic } \\
\text { review }\end{array}$ & $\begin{array}{l}\text { After } 1-2 \text { days physical rest, } \\
\text { patients are encouraged to } \\
\text { become more active while } \\
\text { staying below their symptom } \\
\text { exacerbation threshold. }\end{array}$ & Level 1 \\
\hline \multirow[t]{2}{*}{$\begin{array}{l}\text { What is the effect of cognitive } \\
\text { rest postconcussion on } \\
\text { outcomes including symptom, } \\
\text { emotions, recovery time, } \\
\text { academic success and } \\
\text { participation? }\end{array}$} & Thomas et $a l^{22}$ & $\begin{array}{l}\text { Determined if prolonged } \\
\text { cognitive rest for } 5 \text { days } \\
\text { compared with usual care } \\
\text { (1-2 days cognitive rest) } \\
\text { improved concussion } \\
\text { recovery time and symptoms. }\end{array}$ & RCT & $\begin{array}{l}\text { Prolonged rest group reported } \\
\text { a greater mean PCSS score } \\
\text { and longer time to symptom } \\
\text { resolution than usual care } \\
\text { group. The usual care group } \\
\text { reported more school time than } \\
\text { the prolonged rest group. }\end{array}$ & Level 1 \\
\hline & Taubman et $a l^{23}$ & $\begin{array}{l}\text { Determined the effect of } \\
\text { delayed cognitive rest } \\
\text { compared with immediate } \\
\text { cognitive rest on recovery } \\
\text { time in children with } \\
\text { concussion. }\end{array}$ & Prospective cohort & $\begin{array}{l}\text { Immediate rest group had a } \\
\text { shorter time to clinical recovery } \\
\text { compared with the delayed rest } \\
\text { group. }\end{array}$ & Level 4 \\
\hline
\end{tabular}




\begin{tabular}{|c|c|c|}
\hline Question & Included articles & Objective \\
\hline \multirow[t]{2}{*}{$\begin{array}{l}\text { How much cognitive rest is } \\
\text { recommended/what is the } \\
\text { recommended duration of } \\
\text { cognitive rest and what is the } \\
\text { supporting evidence behind } \\
\text { these recommendations? }\end{array}$} & McCrory et al ${ }^{4}$ & $\begin{array}{l}\text { Provided evidence-based } \\
\text { recommendations to } \\
\text { guide clinical practice of } \\
\text { sport-related concussion } \\
\text { management. }\end{array}$ \\
\hline & Brown et $a l^{28}$ & $\begin{array}{l}\text { Examined the effect of } \\
\text { cognitive activity level on } \\
\text { duration of postconcussion } \\
\text { symptoms. }\end{array}$ \\
\hline
\end{tabular}

\begin{tabular}{|c|c|c|c|c|c|}
\hline \multirow[t]{3}{*}{$\begin{array}{l}\text { What is the recommended time } \\
\text { to progress through the stages } \\
\text { of RTA/RTS protocols? }\end{array}$} & Mckeon et $a l^{30}$ & $\begin{array}{l}\text { Developed probability } \\
\text { estimates for the time } \\
\text { until return to play after } \\
\text { concussion in high school } \\
\text { athletes. }\end{array}$ & $\begin{array}{l}\text { Descriptive } \\
\text { epidemiology } \\
\text { study }\end{array}$ & $\begin{array}{l}\text { Probability of Return } \\
\text { to Play was } 2.5 \% 1-2 \\
\text { days postconcussion; } \\
\text { raised to } 71.3 \% 7-9 \text { days } \\
\text { postconcussion. }\end{array}$ & Level 4 \\
\hline & McCrory et al ${ }^{4}$ & $\begin{array}{l}\text { Provided evidence-based } \\
\text { recommendations to } \\
\text { guide clinical practice of } \\
\text { sport-related concussion } \\
\text { management. }\end{array}$ & $\begin{array}{l}\text { Consensus } \\
\text { statement based } \\
\text { on systematic } \\
\text { review }\end{array}$ & $\begin{array}{l}\text { The time between stages in } \\
\text { graduated protocols should be } \\
\text { a minimum of } 24 \text { hours. }\end{array}$ & Level 1 \\
\hline & O'Neill et $a l^{29}$ & $\begin{array}{l}\text { Conducted a comprehensive } \\
\text { review of the return to learn } \\
\text { literature. }\end{array}$ & Narrative review & $\begin{array}{l}\text { The average time to fully } \\
\text { return to learn varies across } \\
\text { populations; age and gender } \\
\text { are important predictors. }\end{array}$ & Level 4 \\
\hline \multirow[t]{2}{*}{$\begin{array}{l}\text { Is graded exercise of benefit in } \\
\text { achieving a faster RTA? }\end{array}$} & Leddy et $a l^{33}$ & $\begin{array}{l}\text { Investigated the effect of } \\
\text { subsymptom threshold } \\
\text { aerobic exercise compared } \\
\text { with rest. }\end{array}$ & Quasiexperimental & $\begin{array}{l}\text { Recovery time was significantly } \\
\text { lower in the exercise group } \\
\text { than the rest group. Exercise } \\
\text { may reduce the risk of delayed } \\
\text { recovery. }\end{array}$ & Level 2 \\
\hline & Leddy et $a l^{32}$ & $\begin{array}{l}\text { Assessed the effectiveness } \\
\text { of subthreshold aerobic } \\
\text { exercise compared with } \\
\text { stretching. }\end{array}$ & $\mathrm{RCT}$ & $\begin{array}{l}\text { Exercise group recovered in } \\
\text { a median of } 13 \text { days while } \\
\text { stretching group recovered in } \\
17 \text { days. }\end{array}$ & Level 1 \\
\hline
\end{tabular}

BCTT, Buffalo Concussion Treadmill Test; PCSS, Postconcussion Symptom Scale; RCT, randomised controlled trial; RTA, return to activity; RTS, return to school.

participation in school and after-school activities earlier than the participants resting for 5 days. $^{22}$

A quasiexperimental prospective cohort study examined the effect that delayed cognitive and physical rest had on recovery time in paediatric concussion and determined immediate rest was favourable. ${ }^{23}$ Two cohorts were created based on the time between injury and presentation to the authors' primary care paediatric office: an immediate rest group ( 0 days between injury and presentation to the study authors) with 58 participants and a delayed rest group (1-7 days between injury and presentation to the study authors) with 37 participants. ${ }^{23}$ The group undergoing delayed rest had an increased time to clinical recovery compared with the group undergoing rest immediately after their concussive injury. ${ }^{23}$

An additional prospective cohort study ${ }^{24}$ examined the effects of a 1 week prescribed rest period for 13 adolescent athletes with persistent concussion symptoms. These athletes had to have been diagnosed with a concussion and must have had previously undergone concussion testing, must not have been encouraged to rest following the concussion or were noncompliant to rest recommendations and were later referred for clinical assessment due to prolonged symptomatology. ${ }^{24}$ All participants completed neurocognitive testing and on attending a clinic visit were provided with a list of physical and cognitive activities to avoid. Participants were instructed to rest for 1 week. A significant effect of rest on neurocognitive scores and total symptom scores was found. Symptoms improved in $53.8 \%$ of participants, with an additional $30 \%$ endorsing minimal or no symptoms on the Postconcussion Scale prior to the prescription of rest. $^{24}$

The RCT did include risk of bias and subjective outcome measures; however, the study design was strong receiving an evidence rating of Level 1 (22). Due to the limitations in study designs of the prospective cohort studies, the evidence was rated at Level 4 (23).

How much physical rest is recommended/what is the recommended duration of physical rest and what is the supporting evidence behind these recommendations?

Three consensus recommendations created by systematic reviews ${ }^{148}$ addressed this question and were informed 


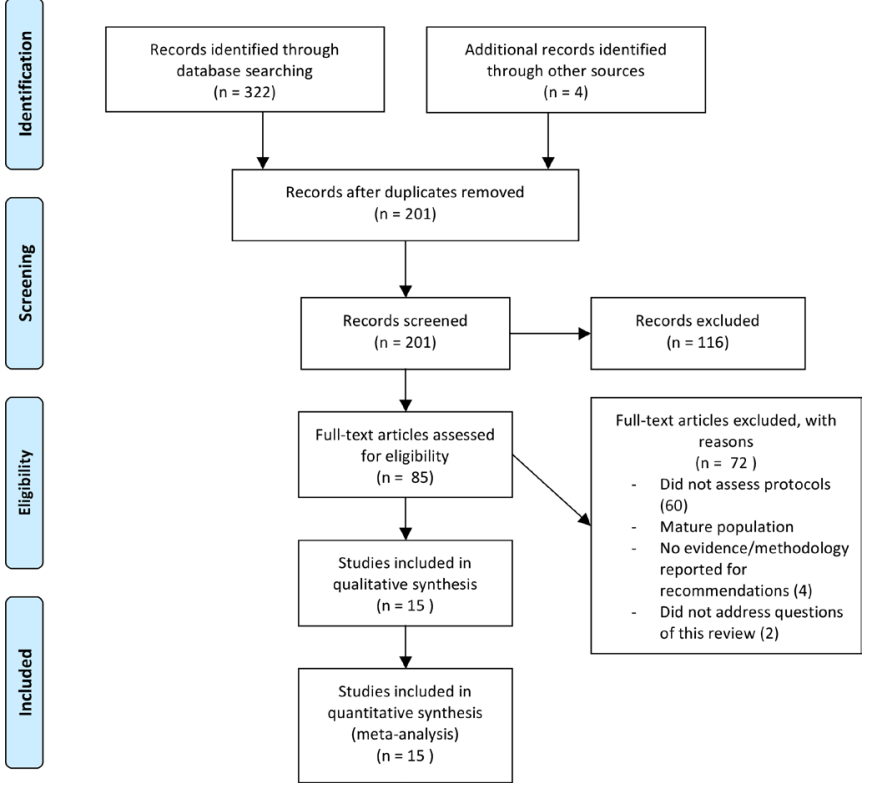

Figure 1 PRISMA 2009 flow diagram. Moher D, Liberati A, Tetzlaff J, Altman DG, The PRISMA Group (2009). Preferred Reporting Items for Systematic Reviews and Meta-Analyses: The PRISMA Statement. PLoS Med 6 (7): e1000097. doi:10.1371/journal.pmed1000097.

by the evidence cited in question 6 . An updated report from the American Academy of Pediatrics also provided recommendations to healthcare providers for the management of paediatric and adolescent concussion and recommendations for physical rest. ${ }^{25}$ All current consensus statements, including most recent updates to the CanChild group's 2015 protocol $^{26}$ recommend 1-2 days of immediate physical rest as part of initiating a gradual resumption of subsymptom physical activity. ${ }^{1425}$

Consensus recommendations from the CISG have traditionally been directed towards an adult population recovering from SRC. ${ }^{4}$ Updates between the $4 \mathrm{th}^{27}$ and 5 th editions ${ }^{4}$ of the CISG recommendations include no longer resting until symptom resolution, ${ }^{27}$ but instead resting for 24-48 hours before gradually reintroducing cognitive and physical activity at a subsymptom threshold level. ${ }^{4}$ No specific recommendations were created for the child or adolescent population in the 4th CISG consensus statement.

The differences in management of youth and adults with concussion are highlighted in the 5th CISG statement, ${ }^{4}$ stating that management for children should consider special paradigms for the developing child in all areas including diagnosis and management. A brief period of cognitive and physical rest with gradual symptom-limited physical and cognitive activity is recommended; however, specifications surrounding length of management are not provided.

In 2015, the CanChild group developed a conservative RTA protocol $^{8}$ for the paediatric population that had been adapted from the 4th CISG consensus. Step 1 of the protocol suggested rest and limited activity until patients had been symptom-free for 1 week. ${ }^{8}$ However, updates to the CanChild group's RTA protocol were made in 2019 to reflect the 5th CISG consensus and now recommend physical rest with symptom-guided activity for 24-48 hours before beginning an RTA/RTS protocol. ${ }^{26}$

Children with concussion should be immediately removed from play and their physical exertion should be limited. ${ }^{25}$ These most current guidelines recommend that children initially undergo 24-48 hours of rest before resuming a gradual RTA that does not exacerbate symptoms. ${ }^{1}$ The level of evidence assigned to these recommendations was Level 1, Level 2 or Level 4 (see table 1) because they were consensus documents based off of systematic reviews of the literature or expert opinion, respectively.

\section{Cognitive rest}

What is the effect of cognitive rest postconcussion on outcomes including symptoms, emotions, recovery time, academic success and participation?

One RCT ${ }^{22}$ and two prospective cohort study ${ }^{2328}$ addressed this question. Cognitive rest immediately following concussive injury for 1-2 days may confer more benefit to reduce symptoms and shorten recovery time compared with delayed and prolonged cognitive rest. ${ }^{22} 2328$

How much cognitive rest is recommended/what is the recommended duration of cognitive rest and what is the supporting evidence behind these recommendations?

One consensus document based on a systematic review ${ }^{4}$ provided recommendations for cognitive rest. These recommendations were the same as for physical rest; to uptake immediate cognitive rest during the first 48 hours postinjury and then become gradually more mentally active while staying below the symptom-exacerbation threshold. ${ }^{4}$ Additionally, a prospective cohort study ${ }^{28}$ found that participants with increased cognitive activity experienced substantially longer symptom duration. This suggests that limiting cognitive activity is associated with decreased symptom duration; however, complete avoidance from cognitive activity is unnecessary as the results of participants grouped into three lower levels of activity had similar trajectories. These results contribute to the current consensus ${ }^{4}$ that limiting strenuous cognitive activity decreases the duration of symptoms of concussion. The evidence behind these recommendations has already been provided in questions $6-8$.

\section{Time progression through guidelines}

What is the recommended time to progress through the stages of RTA and RTS protocols?

Two summary statements provided evidence for the time between stages in RTA/RTS protocols, ${ }^{49}$ and one descriptive study reported the probability of complete RTA in adolescent athletes with concussion. ${ }^{30}$ The RTA/ RTS protocols created by the CanChild group provide recommendations on the time between stages. ${ }^{25} 31$

The time between stages in RTA/RTS protocols should be a minimum of 24 hours to ensure there is no symptom 
exacerbation before beginning the next stage. ${ }^{49}$ The updated CanChild RTA/RTS protocols recommend that children take a minimum 24 hours between steps. $^{26}{ }^{31}$ If symptoms are exacerbated at any point during the protocol, the child should go back one step and remain at that level of activity until they are symptomfree for 24 hours before trying to progress again

Probability estimates predict successful RTP within 7 days after injury, but the times to RTP are highly variable between different strata including sex and age. ${ }^{29} 30$ A descriptive epidemiological study found the majority of high school athletes would return to play within 7-21 days after sustaining a concussion. ${ }^{30}$ This study used Kaplan-Meier curves and time-to-event analysis to determine evidence-based and objective estimates of when an adolescent athlete is likely to return to play; these estimates can be used to describe the likely prognosis of SRC in the paediatric population. ${ }^{30}$ After a new concussion, the probability to RTP within 1-2 days was $2.5 \% .^{30}$ The probability to RTP within 3 days increased to $35 \%$ and within $7-9$ days, it increased to $71.3 \% .^{30}$ These results suggest it is unlikely for an adolescent athlete to RTP within 1-2 days postconcussion and align with the current recommendations to rest for this period of time with the expectation that children with uncomplicated concussions can expect to begin RTP protocols within 3 days after a concussive injury. ${ }^{30}$ Given the methodological limitations of this observational study, it was rated as a Level 4 quality of evidence (table 1 ).

\section{Exertion and exercise}

Is graded exercise/exertion of benefit in achieving a faster return to activity?

Two articles addressed whether graded exercise was of benefit in achieving a faster RTA or recovery: one RCT $^{32}$ and one quasi-experimental study. ${ }^{33}$ Personalised subsymptom threshold aerobic exercise may hasten recovery and lower the risk of delayed recovery in adolescents.

An RCT assessed the effectiveness of subsymptom threshold aerobic exercise compared with a stretching programme in reducing the number of days until recovery in adolescents with a SRC. ${ }^{32}$ Participants in the aerobic group performed exercise daily for $20 \mathrm{~min}$ on a treadmill or stationary bike while under supervision at their prescribed target heart rate $(80 \%$ of the heart rate achieved at symptom exacerbation on the BCTT) while participants in the stretching group were instructed to follow a prescribed programme for 20 min daily. ${ }^{32}$ Participants in the aerobic exercise group recovered in a median of 13 days while participants in the stretching group recovered in a median of 17 days. ${ }^{32}$ This evidence was rated as Level 1 (table 1) due to its multicentre involvement, randomisation and blinding of treating physicians.

A quasiexperimental study investigated the effect of early prescribed aerobic exercise compared with rest on adolescent boy's symptoms and days to recovery after concussion. ${ }^{33}$ These preliminary data suggest that subthreshold aerobic exercise may hasten recovery and has potential to reduce the risk of delayed recovery. ${ }^{33}$ Participants in the aerobic exercise group performed a progressive programme of $20 \mathrm{~min}$ minimum of subsymptom threshold exercise daily, while the rest group was prescribed to rest and given no instructions to exercise. ${ }^{33}$ The recovery time from participants' initial visit was significantly faster in the exercise group compared with the relative rest group. ${ }^{33}$ Four participants in the rest group (13\%) had delayed recovery (symptoms lasting $>30$ days), while none of the participants in the exercise group had delayed recovery. ${ }^{33}$ As a non-randomised cohort study with small sample size and inability to monitor the rest group for strict adherence, this evidence was graded as a Level 2.

Are school accommodations of benefit in having children RTS faster and with fewer academic challenges?

No retrieved articles were found to answer this question.

\section{DISCUSSION}

\section{Summary of results}

The current literature could not address all 12 questions of this systematic review. Despite increased awareness of concussion in the paediatric population and efforts to standardise the management of concussion through RTA and school protocols, research that has evaluated the effectiveness of these protocols or the components on which they are based. More research needs to be conducted to determine if these recommendations provide best care to children with concussion.

Recent evidence recommends that youth progress through the initial stages of RTA and RTS protocols simultaneously, but the priority should be on their complete and successful RTS before returning to full contact sport. ${ }^{34}$ CanChild Pediatric Concussion Guidelines now recommend that children complete stages 1-3 of the RTA and RTS protocols together and then fully RTS before revisiting the last stages of the RTA protocol. ${ }^{34}$

Increased adherence to protocols predicted successful return to sport without symptom exacerbation, while prolonged rest and greater adherence to recommendations for rest was found to prolong the time to recovery and increase patient-reported symptoms. This evidence suggests that protocols with short rest periods and graduated physical and cognitive activity may best facilitate successful RTA/RTS while enhancing the patient's experience during recovery.

\section{Exercise and exertion}

The recommendation to participate in exercise during the acute period after concussive injury for paediatric patients has gone through multiple iterations. Traditionally, complete rest until symptom resolution was the mainstay treatment for concussion including youth, athletes and members of the military. ${ }^{11}$ However, if a child has prolonged symptoms, it is unreasonable to expect them to undergo complete physical rest during that 
period and it is no longer supported by recent research. ${ }^{35}$ Recent evidence proposes that complete rest for longer than 72 hours is most likely not beneficial. ${ }^{11}$ Potential consequences of a long period of rest include deconditioning, depression, and a further delay to recovery. ${ }^{11}$

In the literature, both aerobic and stretching programmes have been evaluated, with aerobic exercise showing an appreciable benefit. Aerobic exercise is postulated to help patients with concussion recover more rapidly by improving autonomic nervous system regulation, improving cerebral blood flow regulation and facilitating neuroplasticity. ${ }^{36}$ Early evidence supports that aerobic exercise compared with rest or stretching may reduce symptoms and shorten recovery time in children with concussion. ${ }^{13153233}$

Current recommendations for exercise in the management of paediatric concussion include the following: immediate removal of the child from activity after a suspected concussion, rest for 1-2 days after the diagnosis of concussion has been made and then gradual resumption of exercise at a level below the child's symptom threshold. ${ }^{4}$ Further investigations should be done to better understand the benefit of aerobic exercise compared with stretching programmes, but the strength of existing evidence certainly suggests aerobic exercise has a role to play in recovery postconcussion.

\section{School accommodations}

Though no retrieved articles evaluated the effectiveness of school accommodations, four consensus documents provided recommendations for school accommodations. ${ }^{1929} 37$ Their common goal was to increase student participation without exacerbating symptoms. Medical and school-based teams should collaborate to counsel the student regarding gradually increasing the duration and intensity of academic activities. ${ }^{29}{ }^{37}$ Protocols to RTS need to be personalised based on the severity of symptoms.

A conservative five-step protocol had been developed to help students $\mathrm{RTS}^{9}$ and was recently updated in 2019. ${ }^{31}$ Children are advised to undergo a short phase of cognitive and physical rest with symptom-guided activity during Stage 1 and should stay home from school for at least 24 hours. ${ }^{31}$ Progression to Stage 2 and preparing to RTS is recommended after 24-48 hours of cognitive rest and includes reintroduction of gradual cognitive activity for $30 \mathrm{~min}$ at a time without symptom exacerbation. ${ }^{31}$ Stages 3 and 4 are focused around the gradual RTS and may incorporate modified academics, environmental accommodations and activity restrictions. ${ }^{9} 31$ Students with prolonged symptoms and disturbances to their academics/school attendance may require protection with appropriate federal statutes. ${ }^{1}$

Current systematic reviews have been published that address components of paediatric concussion management; however, they were not included in this review as they did not directly address the questions in this review. The systematic review by Davis $e t a l^{12}$ evaluated and summarised the evidence on the management of
SRC in children and adolscents. ${ }^{12}$ Although this review did not specifically address the research questions examined in the current review, there were relevant findings, including a brief period of cognitive and physical rest is advised following SRC in children. Symptom-limited physical and cognitive activity should then be gradually reintroduced. Suggestions regarding school accommodations and when a child should return to sport are also provided. The Davis et al review also highlights that prolonged rest may prolong symptom duration and is not recommended. ${ }^{12}$ Factors associated with RTS included age, symptom severity, school resources, medical follow-up and certain school subjects such as math as compared with social studies. The review stresses that it is critical that clinicians and educators work together to help the child RTS appropriately. ${ }^{12}$ Another relevant systematic review by Moser et al, examined the precise age that children should be managed differently than adults. ${ }^{38}$ Again, although it did not directly address the research questions posed here, it had some important contributions to the state of current knowledge. One main conclusion of the Moser et al systematic review is that there is little evidence for why current studies and reviews select various age groups and very little research into the effects of concussion on younger populations aged 5-11. A broad age range within the current review was chosen as we agree with Moser et al that recovery may vary between different developmental stages and because there is limited research within this population, a large scope was preferable for comprehensive results.

\section{Limitations of this review}

One limitation of this systematic review was that the literature search retrieved a small number of articles. It is possible that searching more databases could have retrieved a greater number of articles to screen. To address this potential limitation, we built extensive search strategies with the help of an expert for each database and reviewed citations of retrieved articles for other potentially relevant publications.

Few studies assessed the effect of following RTA or RTS protocols, which was the primary objective of this review. Of the articles that were included, only two were RCTs and the rest were non-randomised controlled cohort studies, case series or consensus recommendations based on systematic review. These methodologies are weak in their ability to draw conclusions on the efficacy of an intervention and/or to generate management and treatment recommendations.

The quality of evidence of the retrieved articles was assessed and found to be of lower quality. Risk of clinical ascertainment bias was high in studies that occurred in concussion clinics or paediatric emergency departments. Subjective and self-reported outcome measures also lower the quality of evidence. Symptom score reporting and the time to recovery may be influenced by the nocebo effect.

The multifaceted nature of the protocols also complicates their evaluation. These RTA and RTS protocols are 
not simple singular interventions but rather a collection of multiple components which often depend on subjective symptom-reporting from the patient and interpretation from providers. An area for future consideration is whether components of the protocols can be evaluated independently when trying to establish the effectiveness of the protocols as a whole.

\section{CONCLUSION}

The effectiveness of adhering to RTA and RTS protocols on improving clinical outcomes for children with concussion cannot be concluded due to the paucity of research on this topic. It is clear that protocols for children are different than those for adults and should be used accordingly. Current recommendations for an immediate period of cognitive and physical rest for 1-2 days while initiating a gradual RTA and RTS protocol align with the best available evidence. As RTA/RTS protocols remain the primary management strategy for children postconcussion, there must be more research into their effectiveness. Future investigations in this field should assess the impact of RTS and RTA protocols on patient symptomatology, quality of life and the time to successful RTS and activity.

Acknowledgements The authors would like to thank the participating families in the Back to Play study for their effort and commitment as well as the consulting stakeholders that provided us with clinical expertise, ongoing support and feedback on the development of the protocols.

Contributors CD conceptualised and generated the questions of this review, supervised the research process, contributed to data interpretation and reviewed and revised the manuscript. EDB conducted the literature search, contributed to data collection and interpretation, drafted the initial manuscript and reviewed and revised the manuscript. SR generated the questions of this review, supervised the research process, contributed to data collection and interpretation and reviewed and revised the manuscript. KF conducted initial literature searches, contributed to data collection and reviewed and revised the manuscript.

Funding This study was funded by the CanChild Centre for Childhood Disability Research Internal Grant competition.

Competing interests None declared.

Patient consent for publication Not required.

Ethics approval Ethics approval was not required for this systematic review.

Provenance and peer review Not commissioned; externally peer reviewed.

Data availability statement All data relevant to the study are included in the article or uploaded as supplementary information.

Open access This is an open access article distributed in accordance with the Creative Commons Attribution Non Commercial (CC BY-NC 4.0) license, which permits others to distribute, remix, adapt, build upon this work non-commercially, and license their derivative works on different terms, provided the original work is properly cited, appropriate credit is given, any changes made indicated, and the use is non-commercial. See: http://creativecommons.org/licenses/by-nc/4.0/.

\section{ORCID iDs}

Carol DeMatteo http://orcid.org/0000-0002-0053-2379

E Dimitra Bednar http://orcid.org/0000-0003-3399-4200

\section{REFERENCES}

1 Lumba-Brown A, Yeates KO, Sarmiento K, et al. Centers for disease control and prevention guideline on the diagnosis and management of mild traumatic brain injury among children. JAMA Pediatr 2018;172:e182853.
2 Zemek R, Duval S, DeMatteo C, et al. Guidelines for diagnosing and managing pediatric concussion, 2014. Available: http://onf.org/ system/attachments/265/original/GUIDELINES_for_Diagnosing_ and_Managing_Pediatric_Concussion_Full__v1.1.pdf

3 Langer L, Levy C, Bayley M. Increasing incidence of concussion: true epidemic or better recognition? J Head Trauma Rehabil 2020;35:E60-E66.

4 McCrory P, Meeuwisse W, Dvořák J, et al. Consensus statement on concussion in sport-the $5^{\text {th }}$ international conference on concussion in sport held in Berlin, October 2016. Br J Sports Med 2017;51:838-47.

5 Halstead ME, McAvoy K, Devore CD, et al. Returning to learning following a concussion. Pediatrics 2013;132:948-57.

6 DeMatteo C, McCauley D, Stazyk K, et al. Post-concussion return to play and return to school guidelines for children and youth: a scoping methodology. Disabil Rehabil 2015;37:1107-12.

7 Giza CC, Hovda DA. The new neurometabolic cascade of concussion. Neurosurgery 2014;75 Suppl 4:S24-33.

8 DeMatteo C, Stazyk K, Singh SK, et al. Development of a conservative protocol to return children and youth to activity following concussive injury. Clin Pediatr 2015;54:152-63.

9 DeMatteo C, Stazyk K, Giglia L, et al. A balanced protocol for return to school for children and youth following concussive injury. Clin Pediatr 2015;54:783-92.

10 McLeod TCV, Lewis JH, Whelihan K, et al. Rest and return to activity after sport-related concussion: a systematic review of the literature. J Athl Train 2017;52:262-87.

11 Silverberg ND, Iverson GL. Is rest after concussion "the best medicine?": recommendations for activity resumption following concussion in athletes, civilians, and military service members. $J$ Head Trauma Rehabil 2013;28:250-9.

12 Davis GA, Anderson V, Babl FE, et al. What is the difference in concussion management in children as compared with adults? A systematic review. Br J Sports Med 2017;51:949-57.

13 Grool AM, Aglipay M, Momoli F, et al. Association between early participation in physical activity following acute concussion and persistent Postconcussive symptoms in children and adolescents. JAMA 2016;316:2504.

14 Iverson GL, Gioia GA. Returning to school following sport-related concussion. Phys Med Rehabil Clin N Am 2016;27:429-36.

15 Kurowski BG, Hugentobler J, Quatman-Yates C, et al. Aerobic exercise for adolescents with prolonged symptoms after mild traumatic brain injury: an exploratory randomized clinical trial. $J$ Head Trauma Rehabil 2017;32:79-89.

16 Halstead ME, Walter KD, The Council on Sports Medicine and Fitness. Sport-Related concussion in children and adolescents. Pediatrics 2010;126:597-615.

17 Law M, Stewart D, Pollock N, et al. Critical review form - Quantitative Studies. Hamilton, 1998.

18 Oxford Centre for Evidence Based Medicine(OCEBM). Systematic review critical appraisal Worksheet, 2011. Available: https://www. cebm.net/wp-content/uploads/2019/01/Systematic-Review.pdf [Accessed 15 Apr 2019].

19 OCEBM Levels of Evidence Working Group. The Oxford 2011 levels of evidence. Oxford centre for evidence-based medicine, 2011. Available: https://www.cebm.net/wp-content/uploads/2014/06/ CEBM-Levels-of-Evidence-2.1.pdf [Accessed 15 Apr 2019].

20 Darling SR, Leddy JJ, Baker JG, et al. Evaluation of the Zurich guidelines and exercise testing for return to play in adolescents following concussion. Clin J Sport Med 2014;24:128-33.

21 Moor HM, Eisenhauer RC, Killian KD, et al. The relationship between adherence behaviors and recovery time in adolescents after a sports-related concussion: an observational study. Int J Sport Phys Ther 2015;10:225-33.

22 Thomas DG, Apps JN, Hoffmann RG, et al. Benefits of strict rest after acute concussion: a randomized controlled trial. Pediatrics 2015;135:213-23.

23 Taubman B, Rosen F, McHugh J, et al. The timing of cognitive and physical rest and recovery in concussion. $J$ Child Neurol 2016;31:1555-60.

24 Moser RS, Schatz P, Glenn M, et al. Examining prescribed rest as treatment for adolescents who are slow to recover from concussion. Brain Inj 2015;29:58-63.

25 Halstead ME, Walter KD, Moffatt K, et al. Sport-Related concussion in children and adolescents. Pediatrics 2018;142. doi:10.1542/ peds.2018-3074. [Epub ahead of print: 12 Nov 2018].

26 CanChild. Return to activity guidelines for children and youth, 2018. Available: https://canchild.ca/system/tenon/assets/attachments/000/ 002/642/original/Return_to_Activity_Guideline_WEB_1_Reference. pdf [Accessed 02 Aug 2019]. 
27 McCrory P, Meeuwisse WH, Aubry M, et al. Consensus statement on concussion in sport: the 4th International Conference on concussion in sport held in Zurich, November 2012. Br J Sports Med 2013;47:250-8.

28 Brown NJ, Mannix RC, O'Brien MJ, et al. Effect of cognitive activity level on duration of post-concussion symptoms. Pediatrics 2014;133:e299-304.

29 O'Neill JA, Cox MK, Clay OJ, et al. A review of the literature on pediatric concussions and return-to-learn (RTL): implications for RTL policy, research, and practice. Rehabil Psychol 2017;62:300-23.

30 McKeon JMM, Livingston SC, Reed A, et al. Trends in concussion return-to-play timelines among high school athletes from 2007 through 2009. J Athl Train 2013;48:836-43.

31 Concussion Management. Return to school guidelines for children and youth, 2018. Available: https://canchild.ca/system/tenon/assets/ attachments/000/002/575/original/Return_to_School_Guideline_ WEB_1_.pdf [Accessed 02 Aug 2019].

32 Leddy JJ, Haider MN, Ellis MJ, et al. Early subthreshold aerobic exercise for sport-related concussion: a randomized clinical trial. JAMA Pediatr 2019;173:319-25.
33 Leddy JJ, Haider MN, Hinds AL, et al. A preliminary study of the effect of early aerobic exercise treatment for sport-related concussion in males. Clin J Sport Med 2019;29:353-60.

34 DeMatteo CA, Randall S, Lin C-YA, et al. What Comes First: Return to School or Return to Activity for Youth After Concussion? Maybe We Don't Have to Choose. Front Neurol 2019;10:1-9.

35 Leddy JJ, Haider MN, Ellis M, et al. Exercise is medicine for concussion. Curr Sports Med Rep 2018;17:262-70.

36 Erickson KI, Voss MW, Prakash RS, et al. Exercise training increases size of hippocampus and improves memory. Proc Natl Acad Sci U S A 2011;108:3017-22.

37 Purcell LK, Davis GA, Gioia GA. What factors must be considered in 'return to school' following concussion and what strategies or accommodations should be followed? A systematic review. $\mathrm{Br} \mathrm{J}$ Sports Med 2019;53:250.

38 Moser RS, Davis GA, Schatz P. The age variable in childhood concussion management: a systematic review. Arch Clin Neuropsychol 2018;33:417-26. 